\title{
REVIEW
}

\section{A review of the epidemiology and treatment of Merkel cell carcinoma}

\author{
João Pedreira Duprat,' Gilles Landman, "I, João Victor Salvajoli,"' Eduard Rene Brechtbühl' \\ 'Hospital do Câncer AC Camargo, Department of Skin Câncer, São Paulo/SP, Brazil. "Hospital AC Camargo - Post Graduation, São Paulo/SP, Brazil.

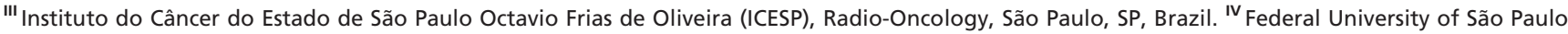 \\ Department of Pathology, São Paulo/SP, Brazil.
}

Merkel cell carcinoma is a very rare and aggressive neoplasm. Due to its rarity, therapeutic guidelines are not well established, especially for regionally advanced disease. Articles in English, French, Italian, Portuguese, and Spanish from the last 20 years were identified in MEDLINE and reviewed. The key word "Merkel" was used for the search, relevant articles were selected, and their references were examined. The most important articles related to epidemiology, genesis and treatment were reviewed. The incidence of Merkel cell carcinoma is increasing due to the advancing age of the population, higher rates of sun exposure and an increasing number of immunocompromised individuals. With regard to etiology, the recently described Merkel Cell polyomavirus is thought to play a role. Either local or regional surgical intervention remains the standard of care, but adjuvant radiotherapy or radiotherapy as a primary treatment have been discussed as reasonable therapeutic options. An update on this rare neoplasia is essential because of its increasing incidence and changing treatment options.

KEYWORDS: Carcinoma, Merkel CELL; Literature review; Radiotherapy; Polyomavirus.

Duprat JP, Landman G, Salvajoli JV, Brechtbühl ER. A review of the epidemiology and treatment of Merkel cell carcinoma. Clinics. 2011;66(10):18171823.

Received for publication on March 11, 2011; First review completed on April 18, 2011; Accepted for publication on May 30, 2011

E-mail: jduprat@uol.com.br

Tel.: 5511 2189-5135

\section{INTRODUCTION}

Merkel Cell Carcinoma (MCC) is a very rare and aggressive neoplasm. Due to its rarity, therapeutic guidelines are not well established, especially for regionally advanced cases.

\section{METHOD}

The MEDLINE database was searched for articles written in English, French, Italian, Portuguese, and Spanish. The key word "Merkel" was used as the basis for these searches. Relevant articles were selected, and their references were also evaluated.

\section{DISCUSSION}

\section{Epidemiology and Etiopathology}

Merkel Cell Carcinoma (MCC) is a rare and aggressive neoplasia that was first described in 1972 by Toker. ${ }^{1}$ This tumor likely originates from a cutaneous mechanoreceptor cell (Merkel cell) located in the basal layer of the epidermis. In the last decade, reports on Merkel cell carcinoma have increased significantly, primarily due to the advent of new and specific immunohistochemical staining methods. This

Copyright @ 2011 CLINICS - This is an Open Access article distributed unde the terms of the Creative Commons Attribution Non-Commercial License (http:// creativecommons.org/licenses/by-nc/3.0/) which permits unrestricted noncommercial use, distribution, and reproduction in any medium, provided the original work is properly cited.

No potential conflict of interest was reported. unusual cutaneous neuroendocrine neoplasia has many synonyms including "cutaneous neuroendocrine carcinoma," "cutaneous trabecular carcinoma," and "small cell primary cutaneous carcinoma".1,2 Currently, 950 to 1,300 cases of MCC are diagnosed per year in the United States. This number appears to be increasing due to the advancing age of the population, the higher incidence of damaging sun exposure, and increasing numbers of immunocompromised individuals. ${ }^{3-7}$ Feng et al. recently described a polyomavirus isolated from MCC specimens, which may explain why MCC is more frequently observed in immunocompromised patients. These authors studied ten tumors and detected the virus in eight cases. In six of the eight positive tumors, the virus was integrated into the tumor genome. In non-MCC patients, integration was observed in $16 \%$ of cases. ${ }^{8}$

The estimated annual incidence of MCC is 0.23 per 100,000 individuals for Caucasians, whereas the incidence in those of African descent is 0.01 per 100,000 and appears to be even lower in Polynesians. Merkel cell carcinoma occurs predominantly in elderly persons, with a mean of 69 yearsold at diagnosis. ${ }^{9-11}$ Males are affected more commonly than females (61\% male vs. $39 \%$ female). ${ }^{12}$ Other tumors, such as squamous cell carcinoma and chronic lymphocytic leukemia, are also common in this population. ${ }^{11}$

Angiogenesis has been described by many authors in this rare tumor. Gaudin and Rosai described a vascular distribution pattern common to Merkel and other neural and neuroendocrine neoplasms characterized by tufts of vessels, similar to a glomeruloid pattern, or long cords of vessels. ${ }^{13}$ They proposed that this characteristic pattern may 
Table 1 - TNM Classification.

\begin{tabular}{lc}
\hline & Tumor (T) \\
\hline T1 & $\leq 2 \mathrm{~cm}$ tumor size \\
T2 & $>5 \mathrm{~cm}$ but no more than $5 \mathrm{~cm}$ \\
T3 & $>2 \mathrm{~cm}$ (N) \\
T4 & Nodal (N) \\
CN0 & invasion of bone, cartilage \\
PN1 & node negative by clinical exam (clinical or imaging exam) \\
N1 & node negative by pathologic exam \\
N1a & metastasis in regional node \\
N1b & micrometastasis (sentinel node or elective lymphadenectomy) \\
N2 & macrometastasis (clinically detectable, confirmed by surgery or fine-needle aspiration) \\
in-transit metastasis & Metastasis (M) \\
M0 & no distant metastasis \\
M1 & metastasis to skin, subcutaneous tissues or distant lymph nodes \\
M1a & metastasis to lung \\
M1b & metastasis to all other visceral sites \\
M1c &
\end{tabular}

be caused by angiogenic factors produced by these tumors. Furthermore, Kukko et al. analyzed the expression of vascular endothelial growth factor receptor-2 (VEGFR-2) in Merkel tumors and found a strong positive correlation between the presence of VEGFR-2, tumor size and metastatic potential. ${ }^{14}$ In that study, the authors suggested that antiangiogenic therapy could help control the tumor, but this was not analyzed experimentally. It has been shown in experimental models of MCC that inhibitors of the mTor pathways result in reduced VEGF production and angiogenesis. ${ }^{15}$

Recently, an interesting study was conducted by Vazmitel et al. ${ }^{16}$ involving 92 cases of MCC. They found prominent vascular alterations in 18 cases $(20 \%)$. Pericyte hyperplasia was observed in ten cases (11\%) among others six different patterns. In this interesting study, the presence of HHV-8 was analyzed because this virus is known to stimulate angiogenesis. However, HHV-8 was not detected with the polymerase chain reaction.

Studies have been conducted on many tumors, including MCC, involving mTor receptors and the AKT/PI3C pathway. mTor (Mammalian Target of Rapamycin) is a protein kinase and a member of the PIKK family that controls cell growth. mTor is regulated by many factors, such as growth factors, hormones (insulin), and the PI3K/Akt pathway. This pathway is initiated by growth factor receptors, such as IGFR (Insulin-like Growth Factor Receptor), PDGFR (PlateletDerived Growth Factor Receptor), EGFR (Epidermal Growth Factor Receptor), and the HER family. ${ }^{17,18}$ In this particular pathway, inactivation of PTEN, which commonly occurs in human tumors, is antagonistic to PI3K and results in increases in PIP3. PI3K activation and accumulation of PIP3 causes translocation of Akt to the plasma membrane, where Akt is activated. These steps initiate anti-apoptotic pathways and stimulate the cell cycle via a series of factors, including mTOR. Akt/mTOR can regulate suppression of p53, and Akt can activate mdm2 and promote p53 degradation. In models of MCC, inhibition of Ras causes apoptosis with p53 degradation, so it is very likely that this pathway is involved in MCC. ${ }^{19,20}$

It is well accepted that Merkel carcinoma commonly occurs in immunocompromised patients, and in this population, changing the immunosuppression regimen from calcineurin inhibitors (azathioprine and cyclosporine) to serolimus results in better cure rates and regression of tumors. ${ }^{21}$ Serolimus (rapamycin) acts both via the inhibition of the mTOR pathway and by diminishing angiogenesis. ${ }^{22}$ It has been tested prospectively after transplants, and there was a significant reduction of skin and non-skin cancers. ${ }^{23}$ Furthermore, serolimus has been tested for MCC. ${ }^{19}$

In an experimental model of MCC, the use of imatinib has been tested. It has been suggested that an autocrine and paracrine activation of KIT receptors in MCC cell lines occurs via stem cell factor (SCF) and induces the MAPK pathway and AKT activation. Although MCC cells display some response to imatinib, a high dose is necessary to obtain cell death. However, relapse has been observed and is most likely due to direct activation of MEK1 and AKT, which induces further proliferation and anti-apoptosis effects, respectively. This pathway is promising as a novel therapeutic option for this tumor. ${ }^{24}$

\section{Diagnosis}

MCC occurs predominantly in the head and neck (41 to $50 \%$ ), followed by the extremities (32 to 38\%) and trunk (12 to $14 \%$ ). Typically, this neoplasm presents as a rapidly growing, dome-shaped red or bluish nodule. ${ }^{10,12,25}$ In addition, the tumor may sometimes have a plaque-like appearance with small satellite lesions. ${ }^{3}$

Diagnosis is usually established only after biopsy. Similar to other neuroendocrine tumors, small round to ovoid cells with hyperchromatic nuclei and frequent mitosis or apoptosis are commonly observed. The architecture is often variable and includes trabecular, nodular and diffuse patterns. Sometimes, it is difficult to differentiate MCC from other small cell tumors, and in these cases, immunohistochemical staining and/or electron microscopy must be used. MCC stains positively for neuron-specific enolase, synaptophysin, chromogranin, cytokeratin 20 (in a characteristic dot-like pattern) and CAM 5.2 and is negative for S100, desmin and common leukocyte antigens. ${ }^{10}$ Cytokeratin-20 expression is detected in 89 to $100 \%$ of MCC cases as well as in $30 \%$ of small-cell lung tumors. ${ }^{26}$

\section{Stage Classification}

Yiengpruksawan ${ }^{27}$ proposed a stage classification for MCC as follows: stage I would be restricted to the skin, stage II would include nodal metastasis, and stage III would be 
Table 2 - Staging System.

\begin{tabular}{lcccc}
\hline Stage & & & & $\begin{array}{c}\text { Five-year } \\
\text { Survival (\%)* }\end{array}$ \\
\hline 0 & Tis & N0 & M0 & \\
IA & T1 & pN0 & M0 & 79 \\
IB & T1 & CN0 & M0 & 60 \\
IIA & T2/T3 & pNO & M0 & 58 \\
IIB & T2/T3 & CNO & M0 & 49 \\
IIC & T4 & N0 & M0 & 47 \\
IIIA & Any T & N1a & M0 & 45 \\
IIIB & Any T & N1b/N2 & M0 & 30 \\
IV & Any T & Any N & M1 & 18 \\
\hline
\end{tabular}

* (Lemos)

characterized by distant metastasis. Later, stage I disease was classified as IA $(\leq 2 \mathrm{~cm})$ or IB $(>2 \mathrm{~cm})$ based on publications by Yiengpruksawan and Allen. ${ }^{25,27,28}$ However, that study was not able to show any statistical differences in the prognosis between tumor size groups. In a study of 251 patients, Allen et al. showed that the proposed stage system with the division of IA and IB resulted in a different prognosis; thus, they used a four-stage system defined as follows: Stage I T (tumor size) $<2 \mathrm{~cm}$, Stage II T $\geq 2 \mathrm{~cm}$ with no evidence of regional or distant disease, Stage III with positive lymph nodes in the drainage basin, and Stage IV with distant metastasis. After a forty-month average followup, the survival rates were $81 \%$ for Stage I, 67\% for Stage II, $52 \%$ for Stage III, and $11 \%$ for Stage IV. ${ }^{29}$ Pitale et al. did not observe any influence of the tumor size on the prognosis of 306 patients, but their meta-analysis was a summary of the literature and did not represent data from a single institution. ${ }^{30}$ Lemos et al. evaluated 2,856 patients and were able to analyze the impact of tumor size with $1-\mathrm{cm}$ increments. They found that the most important difference was between $\leq 2 \mathrm{~cm}$ and more than $2 \mathrm{~cm}$ (five-year survival rate of $66 \%$ vs. $51 \%$, respectively; $p<0.0001)$. Interestingly, tumors that are $<1 \mathrm{~cm}$ are associated with only minimal improvement in survival when compared with those that are 1 to $2 \mathrm{~cm}$ in diameter (69\% vs. $61 \%$, respectively). ${ }^{12}$

Nodal disease is an important negative prognostic factor for this type of tumor. Clinical versus pathological staging seems to be important in prognosis and treatment; patients with a clinically enlarged node had a worse prognosis than those whose nodes were evaluated histopathologically by sentinel lymph node biopsy, fine needle aspiration or elective lymphadenectomy. ${ }^{12}$ Even in the tumor $(\mathrm{T})$ category, the authors categorized the tumors as pathologically negative or clinically negative nodes, with different prognoses (Tables 1 and 2). It is noteworthy that approximately 50 to $70 \%$ of all patients will develop lymph node metastases, and of these patients, 33 to $70 \%$ will develop distant disease. ${ }^{1,2,30-35}$ The most frequent sites of metastasis are liver $(13 \%)$, bone (10-15\%), lung (10-23\%), brain $(18 \%)$, distant skin (9-30\%) and distant lymph nodes $(9 \%) .{ }^{29,36-38}$

In the largest patient cohort of patients from the American National Cancer Database, Lemos et al. evaluated the mortality of each clinical presentation and adjusted for age. For the overall population, the 5 -year survival was $54 \%$; for those with local, nodal and distant disease at presentation, these values were 64,39 , and $18 \%$, respectively. ${ }^{12}$

The Seventh Edition of AJCC ${ }^{39}$ integrates Lemos et al.'s findings, as summarized in Table 2 (excluded Tx and T0).
It was possible, with a greater cohort of patients, to show that in the nodal-negative group clinically evaluated, relative survival was worse when compared to pathologyical proof, such as sentinel, fine-needle or elective lymph node biopsy (HR 1.80, 95\% confidence interval 1.4-2.4, $p<0.0001)$. For the positive nodal group, the survival was worse when a node was clinically detected (HR 1.48, 95\% confidence interval 1.1-1.9, $p=0.004) .{ }^{12}$

\section{Treatment}

Due to its rare incidence, there is currently a lack of standard therapeutic procedures ascribed for the treatment of MCC, especially when the disease is locally advanced. Surgical excision and radiotherapy remain the mainstays of therapy in the initial stages. $2,10,25,27,31,32$

\section{Primary Lesion}

Following a confirmatory biopsy of a suspected lesion that confirms the diagnosis, surgery is the usual treatment choice. $^{2,10,27,31,32,36}$ Depending on the physician's and patient's preference, a wide local excision made deep into the muscle fascia or Mohs micrographic surgery can be performed. Both are successful in achieving tumor-free margins and an acceptable level of disease-free survival. Of note, at our institution, the wide margin resection was preferred. If Mohs micrographic surgery (MMC) is performed, adjuvant radiotherapy seems to be essential. In support of this, Boyer et al. conducted a study among patients who underwent Mohs surgery. Twenty patients had radiotherapy as adjuvant treatment, and 25 did not receive any adjuvant radiotherapy. In the adjuvant radiotherapy group, there was no recurrence, but in the Mohs surgery-only group, recurrence was detected in four cases. Given the small study numbers, this difference was not statistically significant. ${ }^{40}$ Since adjuvant radiotherapy is typically performed regardless of a tumor's margins, it is not reasonable to compare wide local excision and MMC. Wide local excision for MCC is often performed as it is performed for melanoma, with $2 \mathrm{~cm}$ margins, if feasible. Unfortunately, there are no prospective studies on the ideal margin. Allen et al., in a study of 251 patients from a single institution, found that obtaining a surgical margin of more than $1 \mathrm{~cm}$ was not associated with decreased local recurrence $(<1 \mathrm{~cm} 9 \%$ vs. $\geq 1 \mathrm{~cm} 10 \%, p=0.8)$. Local recurrence occurred in $18 \%$ of patients with positive margins; if the margins were negative, recurrence occurred in $8 \%$, and this difference was not statistically significant $(p=0.31)$. In addition, in their study, the use of radiotherapy as opposed to surgery did not decrease the local recurrence rate (radiotherapy $10 \%$ vs. no radiotherapy $8 \%, p=0.76$ ). Unfortunately, this was not a randomized study, so patients with tumors $\geq 2 \mathrm{~cm}$ received additional adjuvant radiotherapy $(<2 \mathrm{~cm} 10 \%$ vs. $\geq 2 \mathrm{~cm} 23 \%, p=0.02)$. It is also worth noting that radiotherapy was given only to $12 \%$ of patients, who generally represented the most severe cases; this could have influenced the outcome in patients with positive margins who received adjuvant treatment. ${ }^{29}$ Jabbour et al. $^{41}$ reinforced previous evidence that, if adjuvant radiotherapy is associated, the margin does not interfere with recurrence or survival. Thus, those authors emphasized the benefit of adjuvant radiotherapy administered either locally or regionally.

There are some authors who advocate the use of adjuvant radiotherapy based on histological features, such as thickness 
Table 3 - Radiotherapy: protocols and results.

\begin{tabular}{lcccc}
\hline Author & $\begin{array}{c}\text { Number of } \\
\text { patients }\end{array}$ & $\begin{array}{c}\text { Control primary without } \\
\text { resection } \%\left(\mathbf{n}^{\circ}\right)\end{array}$ & $\begin{array}{c}\text { Control with adjuvant rdt primary }\left(\mathbf{n}^{\circ}\right) / \text { vs. no } \\
\text { radiotherapy }\end{array}$ & Reference \\
\hline Allen & 251 & & $90 \%(32) / 92 \%$ & $(29)$ \\
Warner & 9 & & $100 \%(9) /(0)$ & $(43)$ \\
Boyle & 41 & $36 \%(30)$ & $91 \%(11)$ & $(33)$ \\
Gillenwater \#\# & 66 & & $44 \%(26) 12 \% /(34)$ & $(47)$ \\
Mortier & 26 & $100 \%(9)$ & $93 \%(27) / 0$ & $(50)$ \\
Veness & 43 & $75 \%(43)$ & & $(51)$ \\
\hline
\end{tabular}

\#\# Radiotherapy to primary and lymph node basin - head \& neck.

and angiolymphatic invasion. ${ }^{42}$ Comparison is very difficult because each study's design and characteristics are different; some compare positive margins, some treat exclusively with radiotherapy, and some add the evaluation of the draining lymph node basin. Various protocols reported in reviews are applied to a large number of patients. Table 3 is an effort to compile these trends.

In a study of 17 patients, Warner et al. did not observe a significant impact of a positive sentinel node on the prediction of regional recurrence. However, they did find that radiotherapy had an impact on local and regional control. ${ }^{43}$

Adjuvant radiotherapy is often suggested for large tumors and for cases in which regional disease is present. ${ }^{30,32,33,35,36,44,45}$ In a meta-analysis by Lewis et al. ${ }^{46}$ who compared surgery alone to surgery plus adjuvant radiation, the authors showed a reduction in local and regional recurrence in the combined therapy group. That study encompassed 1,254 patients, and if local radiotherapy was performed, a decrease in local (88 vs. 61\%, respectively; $p<0.001$ ) and regional (77 vs. $44 \%$, respectively; $p<0.001$ ) recurrence was observed, as was an increase in survival (HR $0.63, p=0.02)$. It is very important to note that the group with primary tumors $\leq 2 \mathrm{~cm}$ benefitted the most from radiotherapy. Gillenwater et al. found a statistically significant difference in local recurrence in the head and neck region with radiotherapy $(12 \%$ with vs. $44 \%$ without; $p<0.01)$ and regional therapy (27 vs. $85 \%$; $p<0.01$ ) but did not find a difference in overall survival. ${ }^{47}$ In a retrospective study, Meeuwissen et al. showed that all 38 patients treated with surgery alone relapsed, whereas only 10 in 34 patients treated with surgery plus radiotherapy relapsed. ${ }^{48}$ In that study, the patients treated with surgery plus radiotherapy were treated at a referred radiotherapy facility, therefore attending mostly the recurrences. It was not clear whether the surgeons who referred patients had the skills to treat the disease. $^{3}$

A primary lesion that is not resectable can be treated with radiotherapy as an isolated treatment. The usual dose is 4570 Gy. ${ }^{49}$ Mortier et al. treated nine cases of primary lesions that could not be treated surgically. After a median followup of three years, there was no recurrence. ${ }^{50}$ In a larger series of 43 patients, Veness et al. treated patients who were non-operable because of clinical or local reasons; $77 \%$ of patients had nodal metastasis. In this particularly bad prognosis group, they had only $60 \%$ relapse, which commonly occurred out-of-field. The in-field control was $75 \%$. The overall survival after two and five years was 58 and $37 \%$, respectively. ${ }^{51}$

The Peter MacCallum Cancer Centre in Australia collected robust data on 176 patients. In that cohort, 94\% of patients received radiotherapy. In the multivariate analysis, the dose of radiotherapy was significantly different for locoregional control. They divided their cohort into three groups: a) no radiotherapy, b) radiotherapy $<45$ Gy and c) radiotherapy $\geq 45 \mathrm{~Gy}$; Comparing the control achieved in the groups, respectively was 51 vs. 71 vs. 80 months $p=0.044$ and overall survival, $p=0.005)$. However, only 11 patients received no radiotherapy. ${ }^{52}$

\section{Regional Treatment}

In the absence of clinically positive lymph nodes, most centers will perform a sentinel lymph node biopsy (SLNB) to obtain accurate nodal staging. As stated previously, this is an important prognostic factor. ${ }^{3,6,43,53}$ The SLNB technique is conducted in the same manner as in melanoma patients. Immunohistochemistry for CK-20 is a valuable tool in identifying micrometastases. Allen et al. found $23 \%$ positivity of lymph nodes in patients who underwent pathologic staging of a clinically negative nodal basin (17 patients underwent elective lymph node dissection and 54 had sentinel lymph node biopsy). Paradoxically, if the primary lesion was less than $2 \mathrm{~cm}$, the rate of positive nodes was $24 \%$, and if the tumor was $\geq 2 \mathrm{~cm}$, the rate of positive nodes was $20 \% \quad(p=0.71) .{ }^{29}$ Gupta et al. reviewed 122 patients with MCC who underwent SLNB and observed that $60 \%$ of those patients with a positive sentinel node recurred in three years (compared to a recurrence rate of $20 \%$ in those with negative SLNB). ${ }^{6}$ Warner et al. analyzed 22 papers involving the use of SLNB for MCC and found that among 241 patients, 31\% had metastases. This group experienced recurrence in $19 \%$ of cases. In the negative sentinel node group, the recurrence was $7.5 \% .{ }^{42}$ A positive node, either clinically or pathologically detected, requires the complete removal of all drainage basin lymph nodes. Patients who underwent a lymphadenectomy had longer disease-free survival (28.5 vs. 11.8 months, $p=0.04){ }^{41}$ Follow-up in small groups of patients reinforces this observation. ${ }^{36,38,53,54}$ Mehrany et al. performed a metaanalysis and showed that 15 of 20 patients with positive sentinel lymph nodes subsequently underwent a lymphadenectomy and had no regional recurrence after nine months. In contrast, three of four patients with positive nodes who did not subsequently undergo lymphadenectomy had regional recurrences, with one patient absent from follow-up. ${ }^{53}$ Gupta et al. showed that a sentinel lymph node biopsy is not only important as a prognostic procedure but can also guide therapy. Data from Lemos et al. have shown that there is also a survival benefit in performing SLNB, as already shown in the stage chapter. ${ }^{12}$

There are some questions about false-negative sentinel nodes in MCC because compared to melanoma patients, the mean age is older, and there is a higher incidence in the 
head and neck region. In both situations, higher numbers of false-negatives have been obtained during the sentinel node biopsy evaluation. MCC more frequently invades deep into the tissues, such as deep dermis and subcutaneous layers, affecting different sentinel nodes than those of the melanoma patients. ${ }^{42}$ However, data from AJCC $2010^{39}$ have shown that the value of the procedure is easily demonstrated. Patients with positive sentinel lymph nodes who received adjuvant therapy localized to the nodal positive basin (surgery, radio-, or chemotherapy) had 50\% diseasefree survival at three years, but this was decreased to $0 \%$ if adjuvant therapy was not administered. ${ }^{6}$ As adjuvant therapy, a dose of 40 to $50 \mathrm{~Gy}$ is administered in 2-Gy daily fractions to the primary or regional basin. ${ }^{34,41,43}$

A major discussion in the literature refers to management after a positive node is detected: is it better to perform a complete node dissection, radiotherapy only, or both ${ }^{42}$ The answer remains unclear. Lymphadenectomy associated with radiotherapy in axillary and inguinal regions can lead to substantial lymphedema. In older patients with micrometastases, isolated radiotherapy seems to be a good option. For good performance status, in patients with larger tumors, macrometastases, or extra-nodal invasion, combined therapy is a reasonable option. For patients with less-thanoptimal margins, especially in the head-neck region where adjuvant radiotherapy is planned, it is reasonable to excise lymph nodes close to the positive node basin (if micrometastasis has minimal disease) without performing a complete lymph node dissection. Extrapolating from studies of the primary lesion, there are enough data to support that radiotherapy only applied to the positive sentinel node basin can be a reasonable option, ${ }^{50,51}$ but the data for positive sentinel nodes remain limited. Bichakjian et al. suggested that with the limited available data, radical lymphadenectomy should be considered the first-line treatment for sentinel node positive patients. In cases where surgery is a high-risk procedure for the patient, radiotherapy without surgery should be considered. ${ }^{36}$

If an enlarged regional node is present, lymphadenectomy and adjuvant radiotherapy are often performed. 30,32,33,35,41,44,45 As previously mentioned, in the head and neck region, Gillenwater et al. found that local and regional recurrence differed significantly when patients received radiotherapy, but they did not find differences in overall survival. ${ }^{47}$ Patients receiving radiotherapy had a regional recurrence rate of 27 vs. $85 \%$ compared to those who did not. Disease-free survival increased from eight to twenty-four months if any radiotherapy was applied. ${ }^{41}$ In summary, it seems that adjuvant radiotherapy is beneficial both locally and regionally.

Distant disease occurs in $36 \%$ of patients, regardless of the adjuvant therapy applied. ${ }^{47}$ In addition, adjuvant chemotherapy failed to provide any benefit. Garneski et al. showed that the chemotherapeutic regimen is toxic, and the target population is elderly, leading to a treatment-related death rate of approximately $16 \%$ in patients older than 65 years. Morbidity is also high in these cases, and the chemotherapeutic regimen is adapted from that used for small-cell lung carcinoma. Without evidence of improved outcomes, it does not seem reasonable to take on the risk of such a toxic treatment. ${ }^{29,41,55,56}$

\section{Distant metastasis}

Chemotherapy plays a role in the treatment of distant metastatic disease. The preferred therapeutic regimen consists of platinum-based components, such as cisplatin or carboplatin, plus etoposide or doxorubicin. Response rates of up to $40 \%$ were observed in some studies; however, those who responded did so only for a short time. ${ }^{33,35,44}$

In recurrent disease, the choice of treatment becomes a matter of debate. Many investigators defend radiotherapy as an important part of the treatment for such patients, $27,31,45,57,58$ whereas others believe that chemotherapy should play a role in recurrent disease. However, the results obtained with this therapy have been disappointing. ${ }^{58,59}$

\section{Treatment of in-transit metastasis}

In-transit disease is a common phenomenon in cutaneous melanoma, as well as in MCC patients. ${ }^{46,60}$ For selected patients with in-transit disease or for whom limb amputation would be indicated, local control of the tumor and limb preservation have been achieved with the increased use of hyperthermic isolated limb perfusion with melphalan. ${ }^{60-64}$

Alternative treatment options, such as radiotherapy and chemotherapy, have been reported. For extensive but localized lesions, radiotherapy can be a good option. Mortier et al. treated nine cases of primary lesions that were not eligible for surgical treatment. After a median follow-up of three years, there was no recurrence. ${ }^{49}$

Selected cases with in-transit metastasis may be successfully treated with isolated perfusion of chemotherapeutic agents as an alternative to radical surgery.

We recently published a review of the literature on hyperthermic isolated limb perfusion in MCC, which covered a series of nine cases, including one case in which we performed the operation. Five patients were treated with melphalan alone, and four were treated with melphalan and TNF- $\alpha$. All patients treated with melphalan alone had a complete response, whereas in the melphalan and TNF- $\alpha$ treatment groups there were two complete responses, one partial response, and one patient with no response. ${ }^{63}$

\section{CONCLUSION}

The incidence of MCC is increasing due to the advancing age of the population, a higher incidence of damaging sun exposure, and an increase in the number of immunocompromised individuals. Regarding its etiology of MCC, the recently described Merkel cell polyomavirus must be considered. While local or regional surgical treatment remains the standard of care, adjuvant radiotherapy or radiotherapy alone have been shown to be reasonable therapeutic options.

\section{REFERENCES}

1. Toker C. Trabecular carcinoma of the skin. Arch Dermatol. 1972;105:10710, doi: 10.1001/archderm.105.1.107.

2. Haag ML, Glass LF, Fenske NA. Merkel cell carcinoma. Diagnosis and treatment. Dermatol Surg. 1995;21:669-83.

3. Eng TY, Boersma MG, Fuller CD, Goytia V, Jones WE, 3rd, Joyner M, et al. A comprehensive review of the treatment of Merkel cell carcinoma. Am J Clin Oncol. 2007;30:624-36, doi: 10.1097/COC.0b013e318142c882.

4. Agelli M, Clegg LX. Epidemiology of primary Merkel cell carcinoma in the United States. J Am Acad Dermatol. 2003;49:832-41, doi: 10.1016/ S0190-9622(03)02108-X.

5. Hodgson NC. Merkel cell carcinoma: changing incidence trends. J Surg Oncol. 2005;89:1-4, doi: 10.1002/jso.20167.

6. Gupta SG, Wang LC, Penas PF, Gellenthin M, Lee SJ, Nghiem P. Sentinel lymph node biopsy for evaluation and treatment of patients with Merkel cell carcinoma: The Dana-Farber experience and meta-analysis of the literature. Arch Dermatol. 2006;142:685-90, doi: 10.1001/archderm.142.6. 685. 
7. Busse PM, Clark JR, Muse VV, Liu V. Case records of the Massachusetts General Hospital. Case 19-2008. A 63-year-old HIV-positive man with cutaneous Merkel-cell carcinoma. N Engl J Med. 2008;358:2717-23, doi: 10.1056/NEJMc0707784

8. Feng $\mathrm{H}$, Shuda $\mathrm{M}$, Chang $\mathrm{Y}$, Moore PS. Clonal integration of a polyomavirus in human Merkel cell carcinoma. Science. 2008;319:1096100, doi: 10.1126/science. 1152586 .

9. Miller RW, Rabkin CS. Merkel cell carcinoma and melanoma: etiological similarities and differences. Cancer Epidemiol Biomarkers Prev. 1999;8:153-8.

10. Pectasides D, Pectasides M, Economopoulos T. Merkel cell cancer of the skin. Ann Oncol. 2006;17:1489-95, doi: 10.1093/annonc/mdl050.

11. Kaae J, Hansen AV, Biggar RJ, Boyd HA, Moore PS, Wohlfahrt J, et al. Merkel cell carcinoma: incidence, mortality, and risk of other cancers. J Natl Cancer Inst. 2010;102:793-801, doi: 10.1093/jnci/djq120.

12. Lemos BD, Storer BE, Iyer JG, Phillips JL, Bichakjian CK, Fang LC, et al. Pathologic nodal evaluation improves prognostic accuracy in Merkel cell carcinoma: analysis of 5823 cases as the basis of the first consensus staging system. J Am Acad Dermatol. 2010;63:751-61, doi: 10.1016/j.jaad. 2010.02.056

13. Gaudin PB, Rosai J. Florid vascular proliferation associated with neural and neuroendocrine neoplasms. A diagnostic clue and potential pitfall. Am J Surg Pathol. 1995;19:642-52, doi: 10.1097/00000478-19950600000004 .

14. Kukko H, Koljonen V, Lassus P, Tukiainen E, Haglund C, Bohling T. Expression of vascular endothelial growth factor receptor-2 in Merkel cell carcinoma. Anticancer Res. 2007;27:2587-9.

15. Falcon BL, Barr S, Gokhale PC, Chou J, Fogarty J, Depeille P, et al. Reduced VEGF production, angiogenesis, and vascular regrowth contribute to the antitumor properties of dual mTORC $1 / \mathrm{mTORC} 2$ inhibitors. Cancer Res. 2011;71:1573-83, doi: 10.1158/0008-5472.CAN10-3126.

16. Vazmitel M, Michal M, Shelekhova KV, Sima R, Mukensnabl P, Kazakov DV. Vascular changes in merkel cell carcinoma based on a histopathological study of 92 cases. Am J Dermatopathol. 2008;30:106-11, doi: 10. 1097/DAD.0b013e318162eaa2.

17. O'Reilly KE, Rojo F, She QB, Solit D, Mills GB, Smith D, et al. mTOR inhibition induces upstream receptor tyrosine kinase signaling and activates Akt. Cancer Res. 2006;66:1500-8, doi: 10.1158/0008-5472.CAN05-2925.

18. Jozwiak J, Jozwiak S, Grzela T, Lazarczyk M. Positive and negative regulation of TSC2 activity and its effects on downstream effectors of the mTOR pathway. Neuromolecular Med. 2005;7:287-96, doi: 10.1385/ NMM:7:4:287.

19. Becker JC, Kauczok CS, Ugurel S, Eib S, Brocker EB, Houben R. Merkel cell carcinoma: molecular pathogenesis, clinical features and therapy. J Dtsch Dermatol Ges. 2008;6:709-19, doi: 10.1111/j.1610-0387.2008.06830. $\mathrm{x}$.

20. Jansen B, Heere-Ress E, Schlagbauer-Wadl H, Halaschek-Wiener J, Waltering S, Moll I, et al. Farnesylthiosalicylic acid inhibits the growth of human Merkel cell carcinoma in SCID mice. J Mol Med 1999;77:792-7, doi: $10.1007 / \mathrm{s} 001099900052$

21. Boratynska M, Watorek E, Smolska D, Patrzalek D, Klinger M. Anticancer effect of sirolimus in renal allograft recipients with de novo malignancies. Transplant Proc. 2007;39:2736-9, doi: 10.1016/j.transproceed.2007.08.078.

22. Guba M, von Breitenbuch P, Steinbauer M, Koehl G, Flegel S, Hornung M, et al. Rapamycin inhibits primary and metastatic tumor growth by antiangiogenesis: involvement of vascular endothelial growth factor. Nat Med. 2002;8:128-35, doi: 10.1038/nm0202-128.

23. Campistol JM, Eris J, Oberbauer R, Friend P, Hutchison B, Morales JM, et al. Sirolimus therapy after early cyclosporine withdrawal reduces the risk for cancer in adult renal transplantation. J Am Soc Nephrol. 2006;17:581-9, doi: 10.1681/ASN.2005090993.

24. Krasagakis K, Fragiadaki I, Metaxari M, Kruger-Krasagakis S, Tzanakakis GN, Stathopoulos EN, et al. KIT receptor activation by autocrine and paracrine stem cell factor stimulates growth of merkel cell carcinoma in vitro. J Cell Physiol. 2011;226:1099-109, doi: 10.1002/jcp.22431.

25. Eng TY, Boersma MG, Fuller CD, Cavanaugh SX, Valenzuela F, Herman TS. Treatment of merkel cell carcinoma. Am J Clin Oncol. 2004;27:510-5, doi: 10.1097/01.coc.0000135567.62750.f4

26. Bobos M, Hytiroglou P, Kostopoulos I, Karkavelas G, Papadimitriou CS. Immunohistochemical distinction between merkel cell carcinoma and small cell carcinoma of the lung. Am J Dermatopathol. 2006;28:99-104, doi: 10.1097/01.dad.0000183701.67366.c7.

27. Yiengpruksawan A, Coit DG, Thaler HT, Urmacher C, Knapper WK. Merkel cell carcinoma. Prognosis and management. Arch Surg. 1991;126:1514-9.

28. Allen PJ, Zhang ZF, Coit DG. Surgical management of Merkel cell carcinoma. Ann Surg. 1999;229:97-105, doi: 10.1097/00000658-19990100000013.

29. Allen PJ, Bowne WB, Jaques DP, Brennan MF, Busam K, Coit DG. Merkel cell carcinoma: prognosis and treatment of patients from a single institution. J Clin Oncol. 2005;23:2300-9, doi: 10.1200/JCO.2005.02.329.
30. Pitale M, Sessions RB, Husain S. An analysis of prognostic factors in cutaneous neuroendocrine carcinoma. Laryngoscope. 1992;102:244-9, doi: 10.1288/00005537-199203000-00003.

31. Hitchcock CL, Bland KI, Laney RG, 3rd, Franzini D, Harris B, Copeland EM, 3rd. Neuroendocrine (Merkel cell) carcinoma of the skin. Its natural history, diagnosis, and treatment. Ann Surg. 1988;207:201-7, doi: 10. 1097/00000658-198802000-00015.

32. Cotlar AM, Gates JO, Gibbs FA, Jr. Merkel cell carcinoma: combined surgery and radiation therapy. Am Surg. 1986;52:159-64.

33. Boyle F, Pendlebury S, Bell D. Further insights into the natural history and management of primary cutaneous neuroendocrine (Merkel cell) carcinoma. Int J Radiat Oncol Biol Phys. 1995;31:315-23, doi: 10.1016/ 0360-3016(93)E0110-R.

34. Queirolo P, Gipponi M, Peressini A, Disomma CF, Vecchio S, Raposio E, et al. Merkel cell carcinoma of the skin. Treatment of primary, recurrent, and metastatic disease: review of clinical cases. Anticancer Res. 1997;17:673-7.

35. Westgate SJ. Radiation therapy for skin tumors. Otolaryngol Clin North Am. 1993;26:295-309.

36. Bichakjian CK, Lowe L, Lao CD, Sandler HM, Bradford CR, Johnson TM, et al. Merkel cell carcinoma: critical review with guidelines for multidisciplinary management. Cancer. 2007;110:1-12, doi: 10.1002/cncr. 22765.

37. Sibley RK, Dehner LP, Rosai J. Primary neuroendocrine (Merkel cell?) carcinoma of the skin. I. A clinicopathologic and ultrastructural study of 43 cases.Am J Surg Pathol. 1985;9:95-108, doi: 10.1097/00000478198502000-00004.

38. Messina JL, Reintgen DS, Cruse CW, Rappaport DP, Berman C, Fenske NA, et al. Selective lymphadenectomy in patients with Merkel cell (cutaneous neuroendocrine) carcinoma. Ann Surg Oncol. 1997;4:389-95, doi: $10.1007 / \mathrm{BF} 02305551$

39. Edge SB, Byrd DR, Compton CC. 30 Merkel Cell Carcinoma. In: Edge SB, Byrd DR, Compton CC, editors. AJCC CANCER STAGING MANUALSeventh Edition. Seventh ed. Chicago: Springer New York Dordrecht Heildelberg London. 2010;315-9.

40. Boyer JD, Zitelli JA, Brodland DG, D'Angelo G. Local control of primary Merkel cell carcinoma: review of 45 cases treated with Mohs micrographic surgery with and without adjuvant radiation. J Am Acad Dermatol. 2002;47:885-92, doi: 10.1067/mjd.2002.125083.

41. Jabbour J, Cumming R, Scolyer RA, Hruby G, Thompson JF, Lee S. Merkel cell carcinoma: assessing the effect of wide local excision, lymph node dissection, and radiotherapy on recurrence and survival in earlystage disease-results from a review of 82 consecutive cases diagnosed between 1992 and 2004. Ann Surg Oncol. 2007;14:1943-52, doi: 10.1245/ s10434-006-9327-y

42. Gonzalez RJ, Padhya TA, Cherpelis BS, Prince MD, Aya-Ay ML, Sondak VK, et al. The surgical management of primary and metastatic Merkel cell carcinoma. Curr Probl Cancer. 2010;34:77-96, doi: 10.1016/j.currproblcancer.2010.02.003.

43. Warner RE, Quinn MJ, Hruby G, Scolyer RA, Uren RF, Thompson JF. Management of merkel cell carcinoma: the roles of lymphoscintigraphy, sentinel lymph node biopsy and adjuvant radiotherapy. Ann Surg Oncol. 2008;15:2509-18, doi: 10.1245/s10434-008-9983-1.

44. Fenig E, Lurie H, Klein B, Sulkes A. The treatment of advanced Merkel cell carcinoma. A multimodality chemotherapy and radiation therapy treatment approach. J Dermatol Surg Oncol. 1993;19:860-4.

45. Gollard R, Weber R, Kosty MP, Greenway HT, Massullo V, Humberson C. Merkel cell carcinoma: review of 22 cases with surgical, pathologic, and therapeutic considerations. Cancer. 2000;88:1842-51, doi: 10.1002/ (SICI)1097-0142(20000415)88:8<1842::AID-CNCR13>3.0.CO;2-P

46. Lewis KG, Weinstock MA, Weaver AL, Otley CC. Adjuvant local irradiation for Merkel cell carcinoma. Arch Dermatol. 2006;142:693-700, doi: 10.1001 /archderm.142.6.693.

47. Gillenwater AM, Hessel AC, Morrison WH, Burgess M, Silva EG, Roberts D, et al. Merkel cell carcinoma of the head and neck: effect of surgical excision and radiation on recurrence and survival. Arch Otolaryngol Head Neck Surg. 2001;127:149-54

48. Meeuwissen JA, Bourne RG, Kearsley JH. The importance of postoperative radiation therapy in the treatment of Merkel cell carcinoma. Int J Radiat Oncol Biol Phys. 1995;31:325-31, doi: 10.1016/03603016(94)E0145-A

49. Rao NG. Review of the role of radiation therapy in the management of Merkel cell carcinoma. Curr Probl Cancer. 2010;34:108-17, doi: 10.1016/j. currproblcancer.2010.01.005.

50. Mortier L, Mirabel X, Fournier C, Piette F, Lartigau E. Radiotherapy alone for primary Merkel cell carcinoma. Arch Dermatol. 2003;139:158790, doi: 10.1001/archderm.139.12.1587.

51. Veness M, Foote M, Gebski V, Poulsen M. The role of radiotherapy alone in patients with merkel cell carcinoma: reporting the Australian experience of 43 patients. Int J Radiat Oncol Biol Phys. 2010;78:703-9, doi: 10.1016/j.ijrobp.2009.08.011.

52. Hui AC, Stillie AL, Seel M, Ainslie J. Merkel Cell Carcinoma: 27-Year Experience at the Peter MacCallum Cancer Centre. Int J Radiat Oncol 
Biol Phys. 2010 12(ahead of print). Int J Radiat Oncol Biol Phys. 2011;80:1430-5. Epub 2010 Aug 12, doi: 10.1016/j.ijrobp.2010.04.061.

53. Mehrany K, Otley CC, Weenig RH, Phillips PK, Roenigk RK, Nguyen TH. A meta-analysis of the prognostic significance of sentinel lymph node status in Merkel cell carcinoma. Dermatol Surg. 2002;28:1137; discussion 7, doi: 10.1046/j.1524-4725.2002.02901.x

54. Kokoska ER, Kokoska MS, Collins BT, Stapleton DR, Wade TP. Early aggressive treatment for Merkel cell carcinoma improves outcome. Am J Surg. 1997;174:688-93, doi: 10.1016/S0002-9610(97)00193-1.

55. Poulsen MG, Rischin D, Porter I, Walpole E, Harvey J, Hamilton C, et al. Does chemotherapy improve survival in high-risk stage I and II Merkel cell carcinoma of the skin? Int J Radiat Oncol Biol Phys. 2006 1;64(1):1149, doi: 10.1016/j.ijrobp.2005.04.042.

56. Garneski KM, Nghiem P. Merkel cell carcinoma adjuvant therapy: current data support radiation but not chemotherapy. J Am Acad Dermatol. 2007;57:166-9, doi: 10.1016/j.jaad.2007.03.011.

57. Pacella J, Ashby M, Ainslie J, Minty C. The role of radiotherapy in the management of primary cutaneous neuroendocrine tumors (Merkel cell or trabecular carcinoma): experience at the Peter MacCallum Cancer Institute (Melbourne, Australia). Int J Radiat Oncol Biol Phys. 1988;14:1077-84, doi: 10.1016/0360-3016(88)90382-3.

58. Fenig E, Brenner B, Katz A, Rakovsky E, Hana MB, Sulkes A. The role of radiation therapy and chemotherapy in the treatment of Merkel cell carcinoma. Cancer. 1997;80:881-5, doi: 10.1002/(SICI)1097-0142(19970 901) $80: 5<881:: A I D-C N C R 8>3.0 . C O ; 2-O$.

59. Tennvall J, Biorklund A, Johansson L, Akerman M. Merkel cell carcinoma: management of primary, recurrent and metastatic disease. A clinicopathological study of 17 patients. Eur J Surg Oncol. 1989;15:1-9.

60. Gupta AS HS, Levine EA. Successful treatment of in-transit metastase from Merkel's cell carcinoma with isolated hyperthermic limb perfusion. South Med J. 1998;91:4, doi: 10.1097/00007611-199810001-00002.

61. Olieman AF, Lienard D, Eggermont AM, Kroon BB, Lejeune FJ, Hoekstra $\mathrm{HJ}$, et al. Hyperthermic isolated limb perfusion with tumor necrosis factor alpha, interferon gamma, and melphalan for locally advanced nonmelanoma skin tumors of the extremities: a multicenter study. Arch Surg. 1999;134:303-7, doi: 10.1001/archsurg.134.3.303.

62. Lampreave JL, Benard F, Alavi A, Jimenez-Hoyuela J, Fraker D. PET evaluation of therapeutic limb perfusion in Merkel's cell carcinoma. J Nucl Med. 1998;39:2087-90.

63. Helm KF, Billingsley EY, Zangwill BC, Schwartz RA. Localized limb cutaneous metastases. J Surg Oncol. 1998;67:261-4, doi: 10.1002/ (SICI)1096-9098(199804)67:4<261::AID-JSO10>3.0.CO;2-3.

64. Duprat JP, Domingues AL, Coelho EG, Leal RM, Nishinari K, Neves RI Long-term response of isolated limb perfusion with hyperthermia and chemotherapy for Merkel cell carcinoma. Eur J Surg Oncol. 2009;35: $568-72$ 